\title{
STRESS-DILATANCY FOR SOILS. PART II: EXPERIMENTAL VALIDATION FOR TRIAXIAL TESTS
}

\author{
ZENON SZYPCIO \\ Department of Civil and Environmental Engineering, \\ Białystok University of Technology, Białystok, Poland, e-mail: z.szypcio@pb.edu.pl
}

\begin{abstract}
Different forms of the stress-dilatancy relations obtained based on the frictional theory for the triaxial condition are presented. The analysed test data show that the shear resistance of many soils is purely frictional. The angle $\Phi^{o}$ represents the resistance of the soil as a combined effect of sliding and particle rolling on the macro-scale during shear at the critical frictional state. The stress-plastic dilatancy relations differ not only for triaxial compression and extension but also for drained and undrained conditions. The experiment investigated shows the correctness of the frictional state theory in the triaxial condition.
\end{abstract}

Key words: soil mechanics, stress-dilatancy, triaxial test

\section{INTRODUCTION}

Triaxial tests are the most common tests conducted in soil mechanics laboratories. All of the stresses and strains in a specimen can be determined through the homogeneous deformation of the specimen.

The best known stress-dilatancy relationships for triaxial compression are derived from the critical state theory. The original Cam clay model [26] has a linear relationship in terms of the triaxial stress and strain invariants, while the Modified Cam clay model [23] has a nonlinear form. A simple approach was proposed by Nova [20], introducing an additional material parameter. More accurate stress-strain relations can be obtained using actual state and structure parameters (e.g., [11], [16]-[19], [31], [32]).

Based on energetic considerations, Rowe [25] provided stress-dilatancy relations for triaxial and biaxial conditions.

General stress-plastic dilatancy relationships have the form [28]

$$
\eta=Q-A D^{p}
$$

where

$$
\begin{aligned}
& \eta=q / p^{\prime}, \\
& Q=M^{o}-\alpha A^{o},
\end{aligned}
$$

$A=\beta A^{o}$,

$D^{p}=\frac{\delta \varepsilon_{v}^{p}}{\delta \varepsilon_{v}^{p}}$,

$M^{o}=M_{c}^{o}=\frac{6 \sin \Phi^{o}}{3-\sin \Phi^{o}}$ for triaxial compression,

$M^{o}=M_{e}^{o}=\frac{6 \sin \Phi^{o}}{3+\sin \Phi^{o}}$ for triaxial extension,

$A^{o}=A_{c}^{o}=1-\frac{1}{3} M_{c}^{o}$ for drained triaxial compression,

$A^{o}=A_{c}^{o}=1+\frac{2}{3} M_{c}^{o}$ for undrained triaxial compression,

$A^{o}=A_{e}^{o}=1-\frac{2}{3} M_{e}^{o}$ for drained triaxial extension,

$A^{o}=A_{e}^{o}=1+\frac{1}{3} M_{e}^{o}$ for undrained triaxial extension.

where $\Phi^{o}$ is the critical frictional state angle of shearing resistance and $\alpha$ and $\beta$ are experimental parameters [28].

In addition, $A^{o}<1$ for the drained condition, and $A^{o}>1$ for the undrained condition ([9], [28]).

For the drained condition, the elastic part of the strain increment for medium and large strains may be neglected in the stress-strain relationship, and dilatancy and plastic dilatancy are used interchangeably in this paper.

In this paper, experimental data are chosen that show the stress-dilatancy relationship or for which a simple calculation is able to prove this relation. 


\section{TRIAXIAL COMPRESSION}

For triaxial compression

$$
\begin{gathered}
\frac{\sigma_{1}^{\prime}}{\sigma_{3}^{\prime}}=\frac{3+2 \eta}{3-\eta}, \\
D^{p}=\frac{\delta \varepsilon_{v}^{p} / \delta \varepsilon_{a}^{p}}{1-\frac{1}{3}\left(\delta \varepsilon_{v}^{p} / \delta \varepsilon_{a}^{p}\right)},
\end{gathered}
$$

where $\delta \varepsilon_{a}^{p}=\delta \varepsilon_{1}^{p}$ is the plastic part of the axial strain increment.

Equation (1) has the form

$$
\frac{\sigma_{1}^{\prime}}{\sigma_{3}^{\prime}}=\frac{3+2 M_{c}^{o}-2 A_{c}^{o}\left(\alpha+\beta D^{p}\right)}{3-M_{c}^{o}+A_{c}^{o}\left(\alpha+\beta D^{p}\right)} .
$$

For non-cohesive soils, the mobilized value of the internal friction angle is

$$
\Phi^{\prime}=2 \tan ^{-1} \sqrt{\sigma_{1}^{\prime} / \sigma_{3}^{\prime}}-\pi / 2 .
$$

For the drained condition at the frictional state $(\alpha=0, \beta=1)$

$$
\begin{gathered}
\eta=M_{c}^{o}-\left(1-\frac{1}{3} M_{c}^{o}\right) D^{p}, \\
\frac{\sigma_{1}^{\prime}}{\sigma_{3}^{\prime}}=\frac{1+\sin \Phi^{o}}{1-\sin \Phi^{o}}-\frac{3-\sin \Phi^{o}}{3\left(1-\sin \Phi^{o}\right)} \frac{\delta \varepsilon_{v}^{p}}{\delta \varepsilon_{a}^{p}} .
\end{gathered}
$$

The most popular stress-dilatancy relationships for triaxial compression at the drained condition are shown in Table 1 [3].

Table 1. Stress-dilatancy relationships

\begin{tabular}{|l|c|}
\hline \multicolumn{1}{|c|}{ Theory } & Relationship \\
\hline Original Cam Clay & $D^{p}=M_{c}-\eta$ \\
\hline Modified Cam Clay & $D^{p}=\left(M_{c}-\eta^{2}\right) / 2 \eta$ \\
\hline Nova, 1982 & $D^{p}=\left(M_{c}-\eta\right) /(1-N)$ \\
\hline Rowe, 1962 & $D^{p}=9\left(M_{f}-\eta\right) /\left(9+3 M_{f}-2 M_{f} \eta\right)$ \\
\hline
\end{tabular}

Rowe [25] proposed the stress-strain relationship for $M_{f}=6 \sin \Phi_{f} /\left(3-\sin \Phi_{f}\right)$, where $\Phi_{\mu} \leq \Phi_{f} \leq \Phi_{c v}^{\prime}$.

The Nova [20] stress-dilatancy relationship is identical to equation (6) for $N=(1 / 3) M_{c}^{o}$ and $\Phi^{o}=\Phi_{c v}^{\prime}$ [15].

Figure 1 compares the different stress-plastic dilatancy relationships for the drained triaxial compression of sand. The relationships are very different, especially for negative plastic dilatancy.

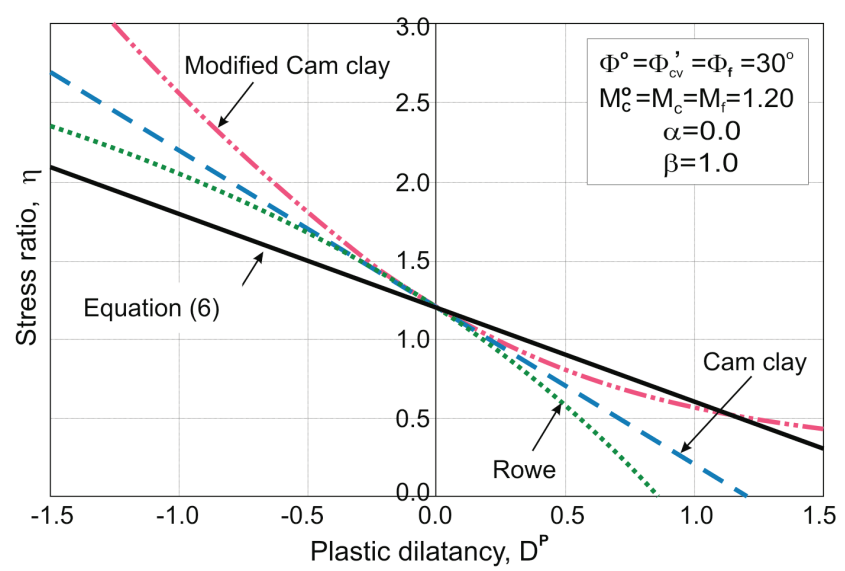

Fig. 1. Comparison of different stress ratio-plastic dilatancy relationships for sand

For the undrained condition at the frictional state $(\alpha=0 ; \beta=1)$

$$
\eta=M_{c}^{o}-\left(1+\frac{2}{3} M_{c}^{o}\right) D^{p}
$$

$$
\frac{\sigma_{1}^{\prime}}{\sigma_{3}^{\prime}}=\frac{\left(1+\sin \Phi^{o}\right)\left(1-\frac{\delta \varepsilon_{v}^{p}}{\delta \varepsilon_{a}^{p}}\right)}{1-\sin \Phi^{o}+\frac{2}{3} \sin \Phi^{o} \frac{\delta \varepsilon_{v}^{p}}{\delta \varepsilon_{a}^{p}}}
$$

It is evident that the stress-strain relationships are very different for drained and undrained conditions.

Figure 2 shows the relationship between the value of $\Phi_{\max }^{\prime}$ and the strain increment ratio at failure for the sand collected by Bishop [4] and the relationship calculated from equations (5) and (7).

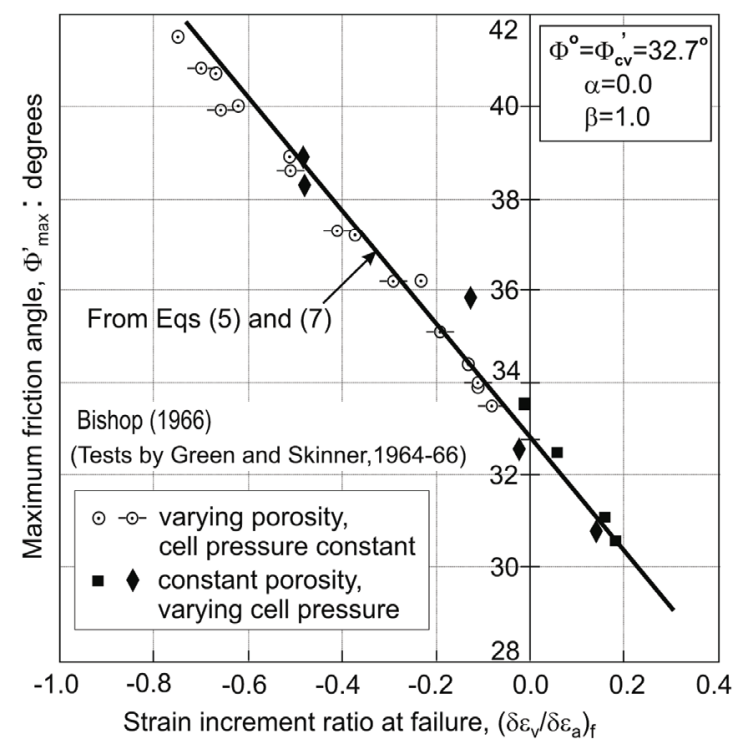

Fig. 2. Relationship between $\Phi_{\max }^{\prime}$ and the strain increment ratio at failure 
At failure, the stress-strain increment ratio relationship for the frictional state gives a good approximation of the experimental data.

A similar relationship between $\Phi_{\max }^{\prime}$ and the strain increment ratio at failure for drained triaxial compression was obtained by Green and Reades [14] for Ham River sand (Fig. 3) and by Cornforth [7] for Brasted sand (Fig. 4).

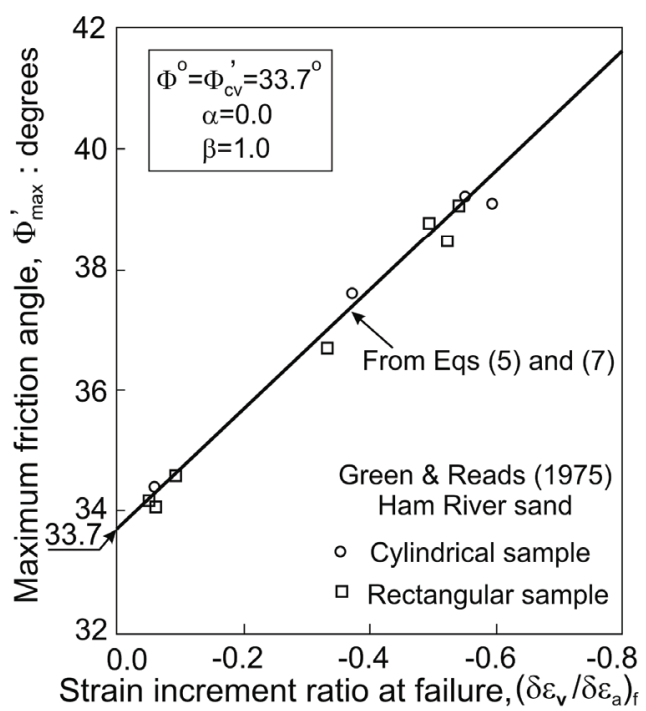

Fig. 3. Relationship between $\Phi_{\max }^{\prime}$

and the strain increment ratio at failure for Ham River sand

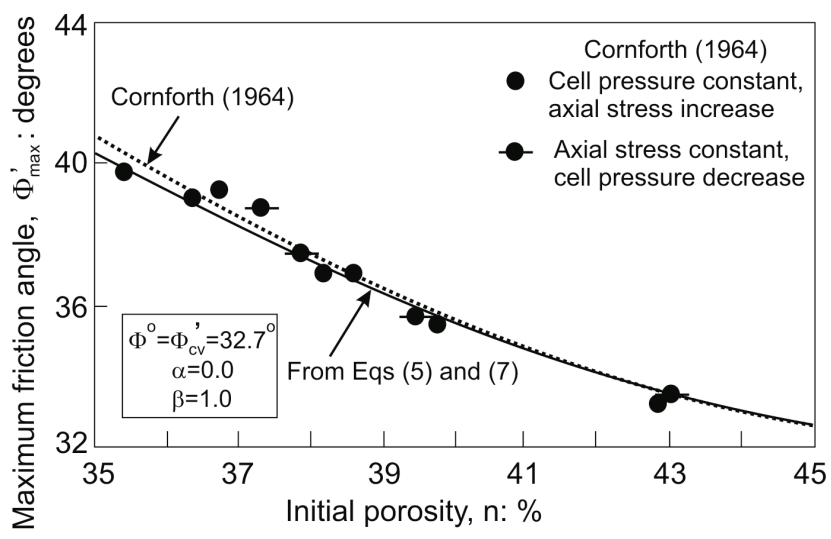

Fig. 4. Strength of Brasted sand at different initial porosities in drained triaxial compression tests

Bolton [5], having analysed the strength and dilatancy of 17 sands of different densities and confining pressures in triaxial compression, proposed the following correlations

$$
\begin{gathered}
\Phi_{\max }^{\prime}-\Phi_{c v}^{\prime}=3 I_{R}, \\
\left(-\frac{\delta \varepsilon_{v}}{\delta \varepsilon_{a}}\right)_{\max }=0.3 I_{R} .
\end{gathered}
$$

The relative density index for quartz sand is

$$
I_{R}=I_{D}\left(10-\ln p^{\prime}\right)-1
$$

where $I_{D}$ is the density ratio and $p^{\prime}$ is in units of kilonewtons per square metre $(\mathrm{kPa})$.

The experimental data collected by Bolton [5] and a straight line representing Bolton's equation, given in equation (10), are shown in Fig. 4. Moreover, Fig. 5 shows a curved line obtained from equations (5) and (7) with $\Phi^{o}=\Phi_{c v}^{\prime}=32^{\circ}$ representing the frictional state.

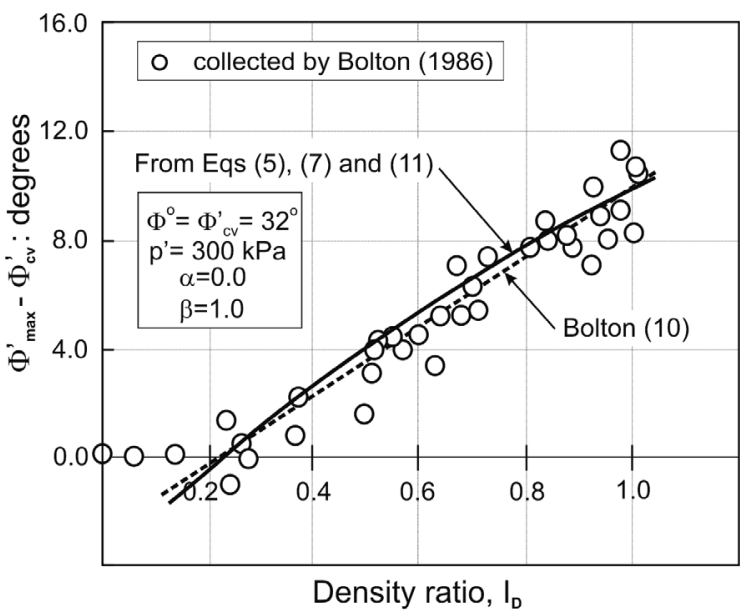

Fig. 5. Relationship between $\left(\Phi_{\max }^{\prime}-\Phi_{c \mathrm{v}}^{\prime}\right)$ and $I_{D}$ for sand

It is evident that the relationship between $\left(\Phi_{\max }^{\prime}-\Phi_{c v}^{\prime}\right)$ and $I_{D}$ obtained from the frictional state theory provides a good approximation of the experimental data. Therefore, Bolton's [5] equation (10) may be treated as an approximation of equation (7) obtained from the frictional state theory with $\Phi^{o}=\Phi_{c v}^{\prime}$ and $\left(-\delta \varepsilon_{v} / \delta \varepsilon_{1}\right)_{\max }=0.3 I_{R}$.

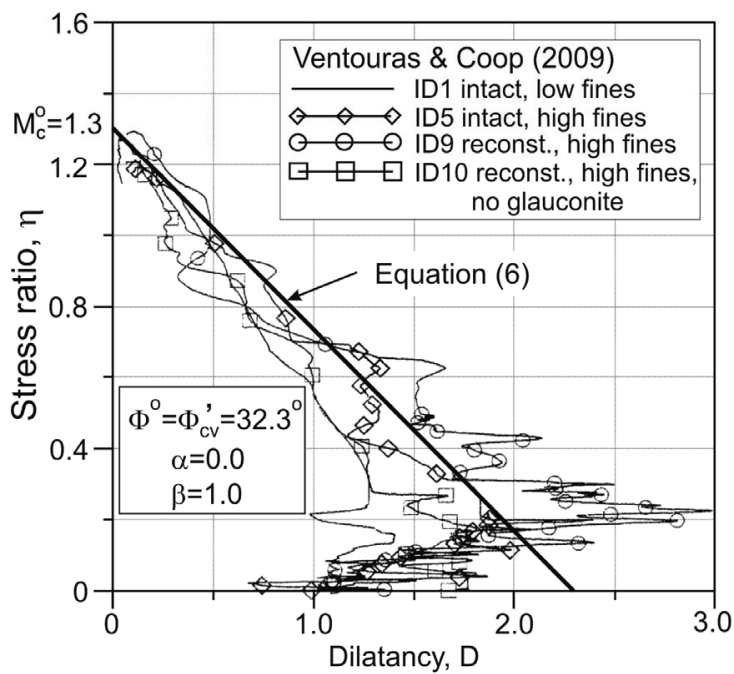

Fig. 6. Stress-dilatancy relationship for Thanet sand 
Thanet sand was extensively investigated by Ventouras [29] in the triaxial condition at small and large strains. Some stress-dilatancy experimental relationships for intact and reconstituted samples with low and high fines are shown in Fig. 6 [30].

Thanet sand clearly exhibits a frictional stressdilatancy relationship $(\alpha=0 ; \beta=1)$ and that $\Phi^{o}=\Phi_{c v}^{\prime}$ for triaxial compression under drained conditions.

Reservoir Sand from a wide range of geographical locations was investigated using high-pressure triaxial tests. The stress-dilatancy behaviour and peak strength for Reservoir Sand-C is shown in Fig. 5 [6].

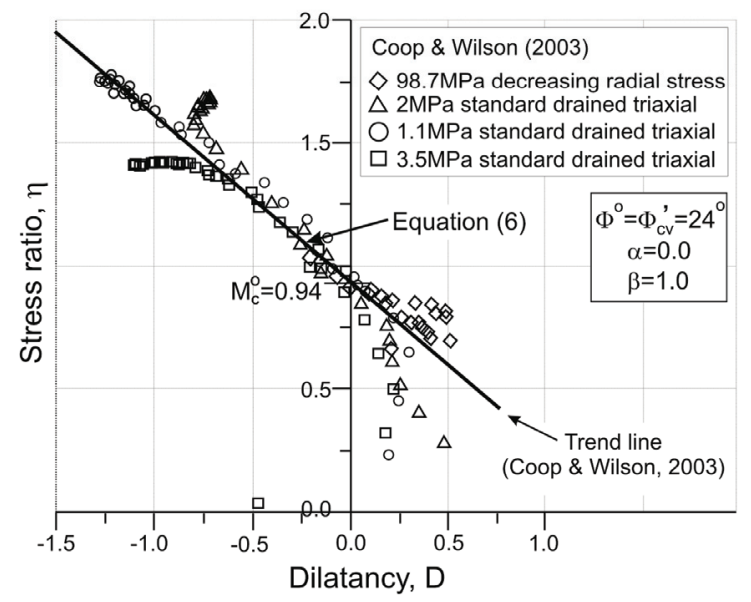

Fig. 7. Stress-dilatancy relationship for Reservoir Sand-C

All triaxial compression tests in the drained condition were terminated shortly after the peak, and the critical state cannot be directly identified from the test data. Figure 7 shows that the stress-dilatancy equation (6) for the frictional state very well approximates the experimental data for $M_{c}^{o}=0.94$ $\left(\Phi^{o}=24^{\circ}\right)$. A very low value of $\Phi^{o}=24^{\circ}[6]$ for predominantly quartz sand suggests that for this sand, $\Phi^{o} \neq \Phi_{c v}^{\prime}$; additional experimental investigations on other soils are needed to prove this.

Sometimes, the frictional angle mobilized at failure is much less than the interparticle friction angle $\Phi_{\mu}$ [2]. Skinner [27], Oda et al. [22] and Oda and Kazama [21] suggested an important role of particle rolling as a micro-deformation mechanism at failure. Therefore, the friction angle $\Phi^{o}$ combines the influences of sliding and rolling at the critical frictional state.

A series of triaxial tests was conducted to investigate the failure behaviour of intact and pluviated samples of Reigate silver sand [10].

Figure 8 shows the maximum stress ratio and dilatancy at failure for both intact and pluviated samples in drained triaxial test at different cell pressures.

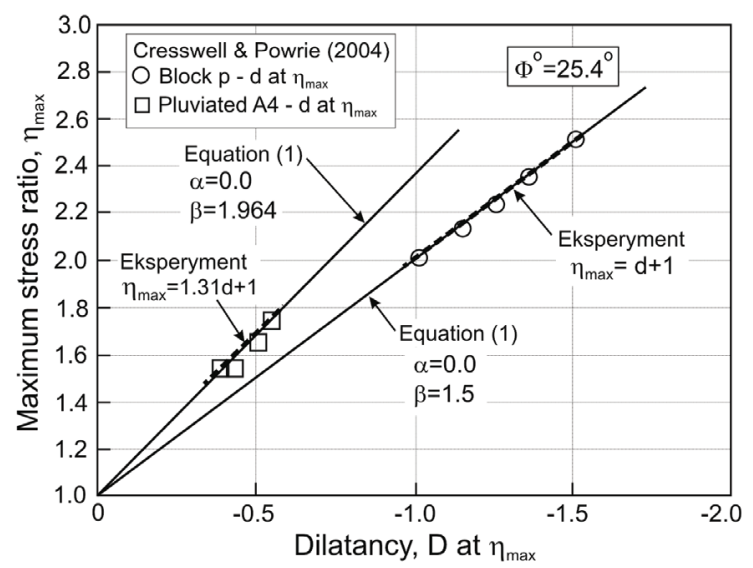

Fig. 8. Maximum stress ratio and dilatancy at failure for Reigate silver sand

The intact samples have a much higher dilatancy and stress ratio than the pluviated samples. For the intact and pluviated samples of Reigate silver sand, both the natural and additional components of the volume change [28] are exhibited at failure $(\beta \neq 1)$. Similar to the triaxial tests of Reservoir Sand, a small value of $M_{c}^{o}=1 \quad\left(\Phi^{o}=25,4^{\circ}\right)$ was observed.

Figure 9 shows data from conventional drained and undrained compression tests on isotropically normally compressed spestone kaolin [24] collected by Wood [34]. In the horizontal axis, as in the original paper [34], angle $\beta=\tan ^{-1}\left(1 / D^{p}\right)$.

The lines representing the frictional state in the drained condition, given by equation (6), and the undrained condition, given by equation (8), are shown. For $\eta>0.5$, the resistance of the soil is purely frictional; the stress-dilatancy relationships are very different for the drained and undrained conditions. Additionally, the lines obtained from the Cam clay and Modified Cam clay models are shown in Fig. 9. This example shows that for soil, very different theoretical models may be proposed based on the same experimental data.

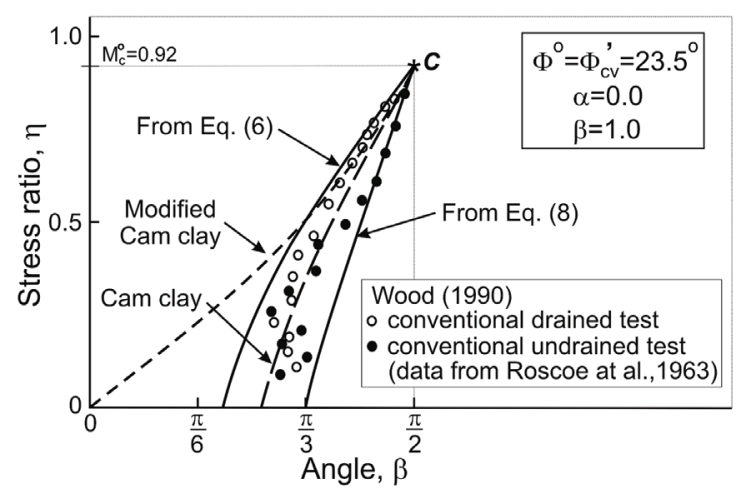

Fig. 9. Stress-dilatancy for spestone kaolin in drained and undrained conditions 
The behaviour of structurally complex clay from the Acquara-Vadoncello landslide (Italy) was extensively investigated by Fearon [12]; the stress-plastic dilatancy relationships are shown in Figs. 10 and 11. Figure 10 shows the stress-plastic dilatancy relationships for drained and undrained triaxial tests on samples taken from the inside of this old landslide.

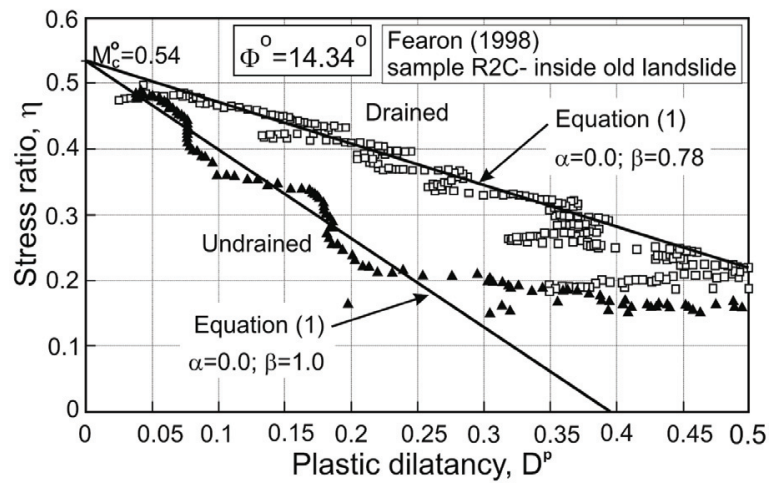

Fig. 10. Stress ratio-plastic dilatancy relationships for drained and undrained triaxial tests of samples from the inside of the Acquara-Vadoncello old landslide

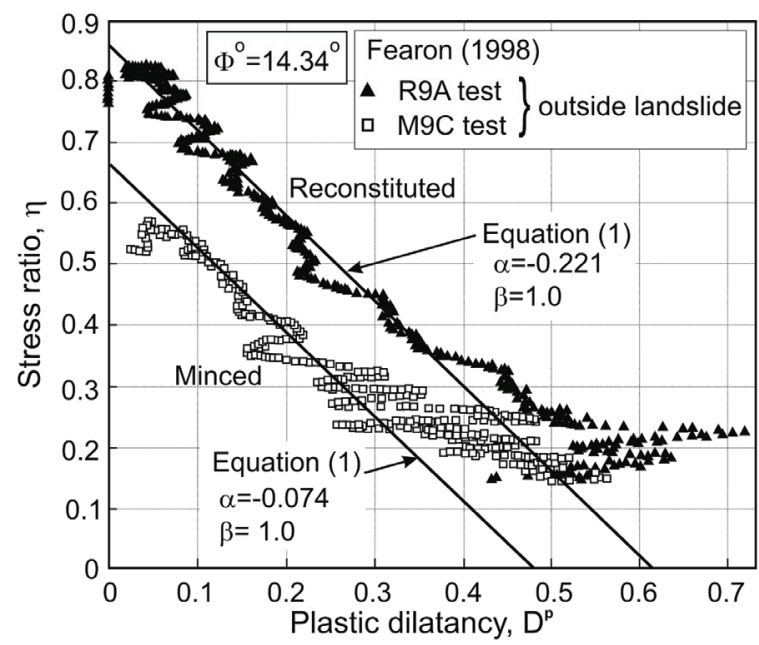

Fig. 11. Stress ratio-plastic dilatancy relationships for minced and reconstituted samples from the outside of the Acquara-Vadoncello landslide

A very good approximation of the experimental data is provided by equation (1) for the undrained condition. Therefore, the behaviour of the samples taken from the old landslide in the undrained tests is purely frictional $(\alpha=0 ; \beta=1)$. However, behaviour that was not purely frictional $(\beta=0.78 \neq 1)$ was observed for the drained test. The value of $\Phi^{o}=14.34^{\circ}$ corresponds to $M_{c}^{o}=0.54$. The values of $\Phi_{c v}^{\prime}$ for this soil depend on the plastic index (PI) and range from $10^{\circ}(\mathrm{PI}=45)$ to $27^{\circ}(\mathrm{PI}=25)$. The residual friction angle is $\Phi_{r}^{\prime} \approx 5^{\circ}[12]$; therefore, $\Phi^{o} \neq \Phi_{c v}^{\prime} \neq \Phi_{r}^{\prime}$.

Figure 11 shows the stress-plastic dilatancy relationships in an undrained triaxial test for reconstituted (sample R9A) and minced (sample R9C) samples taken from the outside of the Acquara-Vadoncello landslide. Unexpectedly, the slopes of the stressplastic dilatancy lines that approximate the experimental data for the reconstituted and minced samples taken from the outside of the landslide and those from the inside of the old landslide are the same and equal $A_{c}^{o}=1.36$. Therefore, it is reasonable to take $M_{c}^{o}=0.54, A_{c}^{o}=1.36$, and $\beta=1$ for all stress-plastic dilatancy relations. A very good approximation of the experimental data is obtained from equation (1) with $\alpha=-0.221$ and $\alpha=-0.074$ for the reconstituted and minced samples, respectively. Parameters $\alpha$ and $\beta$ represent the level of structure degradation, so the method of sample preparation and the strain history clearly result in different experimental stress-dilatancy relationships [13]. In the undrained condition, the slopes of the stress-plastic dilatancy are the same for different samples (Figs. 10 and 11) of structurally complex clay. This experiment sheds new light on the stress-dilatancy relationship for structured soils.

Similar behaviour was observed by Cotecchia and Chandler [8] for Papadei clay.

\section{TRIAXIAL EXTENSION}

For triaxial extension

$$
\begin{gathered}
\frac{\sigma_{1}^{\prime}}{\sigma_{3}^{\prime}}=\frac{3+\eta}{3-2 \eta}, \\
D^{p}=-\frac{\delta \varepsilon_{v}^{p} / \delta \varepsilon_{a}^{p}}{1-\frac{1}{3}\left(\delta \varepsilon_{v}^{p} / \delta \varepsilon_{a}^{p}\right)},
\end{gathered}
$$

and the stress-plastic dilatancy relationship in equation (1) may be written in the form

$$
\frac{\sigma_{1}^{\prime}}{\sigma_{3}^{\prime}}=\frac{3+M_{e}^{o}-A_{e}^{o}\left(\alpha+\beta D^{p}\right)}{3-2 M_{e}^{o}+2 A_{e}^{o}\left(\alpha+\beta D^{p}\right)} .
$$

In the drained condition for the frictional state $(\alpha=0 ; \beta=1)$

$$
\eta=M_{e}^{o}-\left(1-\frac{2}{3} M_{e}^{o}\right) D^{p},
$$




$$
\frac{\sigma_{1}^{\prime}}{\sigma_{3}^{\prime}}=\frac{1+\sin \Phi^{o}-\frac{2}{3} \sin \Phi^{o} \frac{\delta \varepsilon_{v}^{p}}{\delta \varepsilon_{a}^{p}}}{\left(1-\sin \Phi^{o}\right)\left(1-\frac{\delta \varepsilon_{v}^{p}}{\delta \varepsilon_{a}^{p}}\right)}
$$

The Rowe [25] stress-strain relation for sand has the form

$$
\frac{\sigma_{1}^{\prime}}{\sigma_{3}^{\prime}}=\frac{1+\sin \Phi_{f}}{\left(1-\sin \Phi_{f}\right)\left(1-\frac{\delta \varepsilon_{v}}{\delta \varepsilon_{a}}\right)} .
$$

In the undrained condition for the frictional state $(\alpha=0 ; \beta=1)$

$$
\begin{gathered}
\eta=M_{e}^{o}-\left(1+\frac{1}{3} M_{e}^{o}\right) D^{p}, \\
\frac{\sigma_{1}^{\prime}}{\sigma_{3}^{\prime}}=\frac{\left(1+\sin \Phi^{o}\right)}{1-\sin \Phi^{o}-\left(1+\frac{1}{3} \sin \Phi^{o}\right) D^{p}} .
\end{gathered}
$$

A comparison of the Rowe and the frictional state theory of stress-plastic dilatancy relationships for drained triaxial extension tests is shown in Fig. 12.

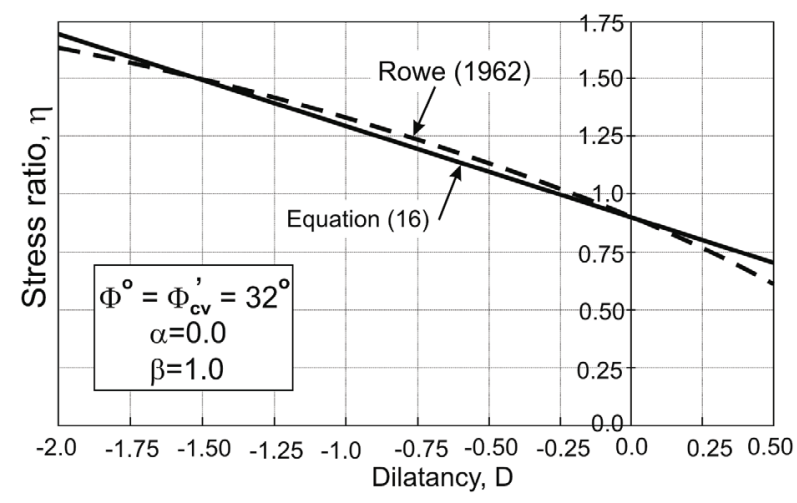

Fig. 12. Stress ratio-dilatancy for sand in drained triaxial extension tests

The stress ratios obtained from the two theories are narrow for negative or small positive values of dilatancy.

The stress ratio-plastic dilatancy relationship at failure for River Walland sand, investigated by Barden and Khayatt [1], is shown in Fig. 13, while that for Brasted sand, investigated by Cornforth [7], is shown in Fig. 14 for the frictional state $(\alpha=0 ; \beta=1)$ and $\Phi^{o}=\Phi_{c v}^{\prime}$.

The theoretical stress-dilatancy relationship approximates the experimental data very well for sand at failure in drained triaxial extension tests.

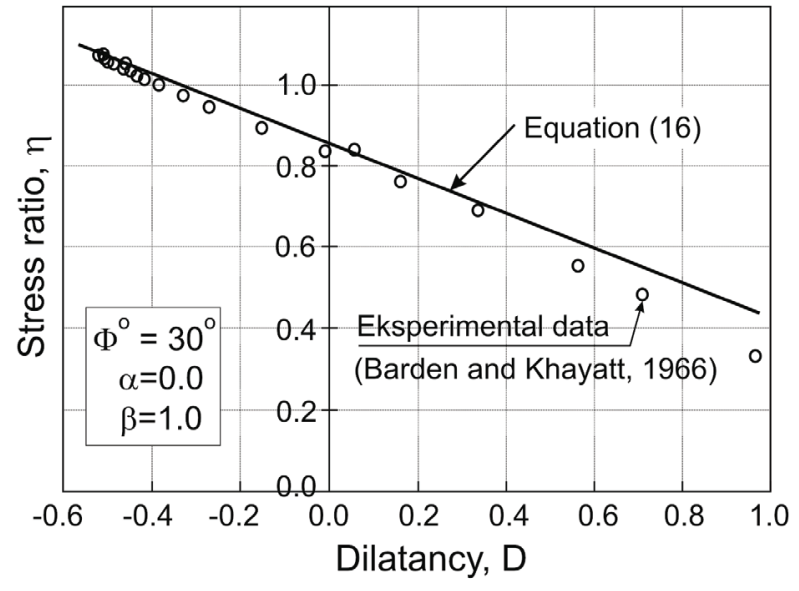

Fig. 13. Stress ratio-dilatancy at failure of River Walland sand

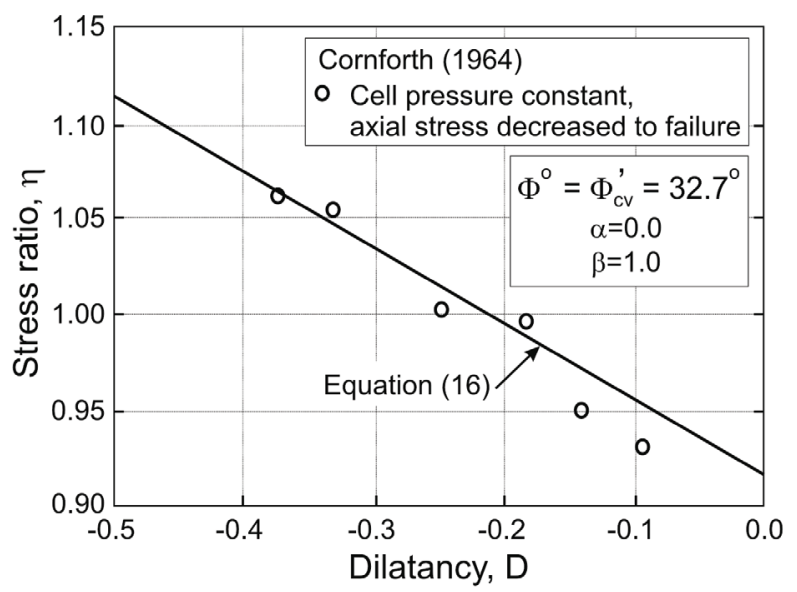

Fig. 14. Stress ratio-dilatancy at failure of Brasted sand

\section{CONCLUSIONS}

The stress-plastic dilatancy relationships differ for triaxial compression and extension in drained and undrained conditions.

The strength of many sands is purely frictional $(\alpha=0 ; \beta=1)$, where $\Phi^{o}=\Phi_{c v}^{\prime}$.

For some soils, the angle $\Phi_{r}^{\prime}<\Phi^{o}<\Phi_{c v}^{\prime}$ represents the combined effect of the sliding and rotation of grains on the macro-scale during shearing at the critical frictional state.

The parameters $\alpha$ and $\beta$ are dependent on the initial soil structure, the stress and strain history and the preparation method of the samples tested.

The stress-dilatancy obtained based on the frictional state theory is correct in the light of the experimental data analysed in this paper.

The complete validation of stress-dilatancy in the triaxial condition needs more experimental investiga- 
tion, especially for structured and transitional soils under drained and undrained conditions for different stress and strain paths.

\section{REFERENCES}

[1] BARDEN L., KHAYATT A., Incremental strain rate ratios and strength of sand in the triaxial test, Geotechnique, 1966, 16, No. 4, 338-357.

[2] BARdet I.P., Proubet J., A numerical investigation of the structure of persistent shear bands in granular media, Geotechnique, 1991, 41, No. 4, 599-613.

[3] BEEn K., JefFeries M., Stress-dilatancy in very loose sand, Canadian Geotechnical Journal, 2004, 41, 972-989.

[4] Bishop A.W., Sixth Rankine Lecture. Strength of soils as engineering materials, Geotechnique, 1966, 16, No. 2, 91-128.

[5] Bolton M.D., The strength and dilatancy of sands, Geotechnique, 1986, 36, No. 1, 65-78.

[6] Coop M.R., Wilson S.M., Behaviour of Hydrocarbon Reservoir Sands and Sandstones, Journal of Geotechnical and Geoenvironmental Engineering, 2003, 129, No. 11, $1010-1019$

[7] CORNFORTH D.H., Some experiments on the influence of strain conditions on the strength of sand, Geotechnique, 1864, 36, No. 1, 65-78.

[8] COTECCHIA F., CHANDLER R.J., The influence of structure on the pre-failure behaviour of a natural clay, Geotechnique, 1997, 47, No. 3. 523-544.

[9] Cotecchia F., Chandler R.J., A general framework for the mechanical behaviour of clays, Geotechnique, 2000, 50, No. 4, 431-447.

[10] Cresswell A., Powrie W., Triaxial tests on an unbonded locked sand, Geotechnique, 2004, 54, No. 2, 107-115.

[11] Cuccovillo T., Coop M.R., On the mechanics of structured sands, Geotechnique, 1999, 49, No. 6, 741-760.

[12] FEARON R., The behaviour of structurally complex clay from Italian landslide, $\mathrm{PhD}$ Thesis. City University London, UK, 1998.

[13] FEARON R.E., CoOP M.R., Reconstitution: what makes an appropriate reference material? Geotechnique, 2000, 50, No. 4, 471-477.

[14] Green G.E., Reades D.W., Boundary conditions, anisotropy and sample shape effects on the stress-strain behaviour of sand in triaxial compression and plane strain, Geotechnique, 1975, 25, No. 2, 333-356.

[15] JEFFERIES M.G., Nor-Sand: a simple critical state model for sand, Geotechnique, 1993, 43, No. 1, 91-103.
[16] JefFeries M.G., Plastic work and isotropic softening in unloading, Geotechnique, 1997, 47, No. 5, 1037-1042.

[17] JefFeries M.G., ShUTtle D.A., Dilatancy in general Cambridge-type model, Geotechnique, 2002, 52, No. 9, 625-638.

[18] Li X.S., Dafalias Y.F., Dilatancy for cohesionless soils, Geotechnique, 2000, 50, No. 4, 449-460.

[19] ManZari M.T., Dafalias Y.F., A critical state two-surface plasticity model for sands, Geotechnique, 1997, 47, No. 2, 255-272.

[20] Nova R., A constitutive model under monotonic and cyclic loading, [in:] Soil mechanics-transient and cyclic loads, G. Pande, O.C. Zienkiewicz (eds.), John Wiley \& Sons, Ltd., New York, 1982, 343-373.

[21] OdA M., KAZAMA H., Microstructure of shear bands and its relation to the mechanisms of dilatancy and failure of dense granular soils, Geotechnique, 1998, 48, No. 4, 465-481.

[22] OdA M., Konishi J., NeMAT-NASSER S., Experimental micromechanical evaluation of strength of granular materials. effect of particle rolling, Mech. Mater., 1982, 1, 267-283.

[23] Roscoe K.H., Burland J.B., On the generalized stressstrain behaviour of 'wet' clay, [in:] Engineering plasticity, J. Heyman, F.A. Leckie (eds.), Cambridge University Press, London, UK, 1968, 535-609.

[24] Roscoe K.H., Schofield A.N., Thurairajah A., Yielding of clays in states wetter than critical, Geotechnique, 1963, 13, No. 2, 211-240.

[25] Rowe P.W., The stress-dilatancy relation for static equilibrium of an assembly of particles in contact, Proc. Roy. Soc., Ser. A, 1962, 269, 500-527.

[26] Schofield A., Wroth C.P., Critical state soil mechanics, McGraw-Hill, London, UK, 1968.

[27] SKINNER A.E., A note on the influence of inter-particle friction on the shearing strength of a random assembly of spherical particles, Geotechnique, 1969, 19, 150-157.

[28] Szypcio Z., Stress-dilatancy for soils. Part I: The frictional state theory, Studia Geotechnica et Mechanica, 2016, Vol. 38, No. 4, 51-57.

[29] Ventouras K., Engineering behaviour of Thanet sand, PhD Thesis. University of London, UK, 2005.

[30] Ventouras K., CoOP M.R., On the behaviour of Thanet Sand: an example of an uncemented natural sand, Geotechnique, 2009, 59, No. 9, 727-738.

[31] WAN R., GUO P., Effect of microstructure on undrained behaviour of sands, Can. Geotech. J., 2001, 38, 16-28.

[32] Wan R., GuO P., AL-Mamun M., Behaviour of granular material in relation to their fabric dependencies, Soils and Foundations, 2005, 45, No. 2, 77-86.

[33] Wood D.M., Soil behaviour and critical state soil mechanics, Cambridge University Press. Cambridge, 1990. 